Article

\title{
Influence of Phase Transformations on Crystal Growth of Stoichiometric Brownmillerite Oxides: $\mathrm{Sr}_{2} \mathrm{ScGaO}_{5}$ and $\mathrm{Ca}_{2} \mathrm{Fe}_{2} \mathrm{O}_{5}$
}

\author{
Monica Ceretti *, Serena Corallini and Werner Paulus \\ Institut Charles Gerhardt, UMR 5253 CNRS-Université Montpellier, C2M, 5 Pl. Eugene Bataillon, \\ 34095 Montpellier, France; serena.corallini1@gmail.com (S.C.), werner.paulus@umontpellier.fr (W.P.) \\ * Correspondence: monica.ceretti@umontpellier.fr; Tel.: +33-04-6714-3746; Fax: +33-04-6714-4290 \\ Academic Editor: Ekaterina Pomjakushina \\ Received: 18 October 2016; Accepted: 8 November 2016; Published: 12 November 2016
}

\begin{abstract}
High quality stoichiometric brownmillerite-type oxide single crystals have been successfully grown by the floating zone method using a mirror furnace. We report here on the growth conditions and structural characterization of two model compounds: $\mathrm{Ca}_{2} \mathrm{Fe}_{2} \mathrm{O}_{5}$ and $\mathrm{Sr}_{2} \mathrm{ScGaO}_{5}$. Both show oxygen deficiency with respect to the average perovskite structure, and are promising candidates for oxygen ion conductivity at moderate temperatures. While $\mathrm{Sr}_{2} \mathrm{ScGaO}_{5}$ single crystals were obtained in the cubic oxygen-deficient perovskite structure, $\mathrm{Ca}_{2} \mathrm{Fe}_{2} \mathrm{O}_{5}$ crystallizes in the brownmillerite framework. Having no cubic parent high temperature counterpart, $\mathrm{Ca}_{2} \mathrm{Fe}_{2} \mathrm{O}_{5}$ crystals were found to be not twinned. We report on structural characterization of the as-grown single crystals by neutron and X-ray diffraction, as well as scanning electron microscopy (SEM) coupled with EDX (Energy Dispersive X-Ray Spectroscopy) analysis and isotope exchange experiments.
\end{abstract}

Keywords: brownmillerite; oxygen ion conduction; single crystal growth; floating zone method; neutron diffraction

\section{Introduction}

In the last decades, brownmillerite type oxides have received considerable attention, because of their rich chemistry, structural complexity, and for their interesting properties and applications [1-8]. With the general formula $\mathrm{A}_{2} \mathrm{BB}^{\prime} \mathrm{O}_{5}$, the brownmillerite framework can be described as an oxygen-anion-deficient perovskite phase, and its structure can be derived from the cubic phase by releasing $1 / 6$ of all oxygen atoms in an ordered way along the [110] direction of the cubic perovskite. Three different prototypes of the general formula $\mathrm{ABO}_{2.5}$ or $\mathrm{A}_{2} \mathrm{~B}_{2} \mathrm{O}_{5}$ can all be obtained from the perovskite structure, modifying every second octahedral layer toward lower coordination transition metal polyhedra, such as a square planar coordination in $\mathrm{LaNiO}_{2.5}[8,9]$ or a square-based pyramid coordination in $\mathrm{CaMnO}_{2.5}[10,11]$. The brownmillerite structure is finally characterized by tetrahedral layers containing isolated $\mathrm{MO}_{4}$ tetrahedral zigzag chains, which are separated by $1 \mathrm{D}$ oxygen vacancy channels, alternating with octahedral layers (see Figure 1). On top of the basic brownmillerite framework, several modulated superstructures as well as disorder in the stacking sequence have been characterized, leading in total to a more complex arrangement of the octahedral and tetrahedral layers [1-4].

The formation of empty 1D oxygen vacancy channels along the [100] direction in the brownmillerite network (see Figure 1) goes along with an orthorhombic symmetry and related cell parameters of $a_{\text {brown }} \cong a_{\text {perov }} \sqrt{2}, b_{\text {brown }} \cong 4 a_{\text {perov, }}$ and $c_{\text {brown }} \cong a_{\text {perov }} \sqrt{2}$ with respect to the perovskite parent structure. However, the attribution of the space group in some cases remains ambiguous between Pnma, Imma, and $I 2 m b$. The associated structural difference is important, however, since Pnma and $I 2 m b$ result into ordered $\left(\mathrm{BO}_{4}\right)_{\infty}$-tetrahedral chains, while Imma yields an average and 
disordered orientation, which can be static or dynamic. The latter case has been discussed as an indicator favouring low temperature oxygen mobility in brownmillerite frameworks [12].
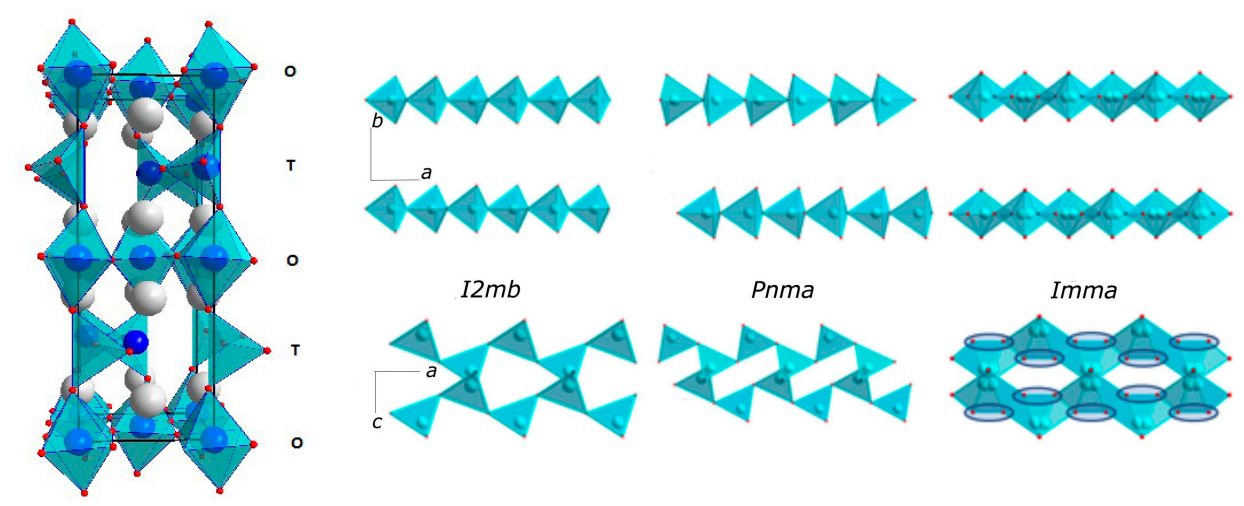

Figure 1. Brownmillerite structure with alternating octahedral $(\mathrm{O})$ and tetrahedral $(\mathrm{T})$ chains. On the right, different switching arrangements for the $\left(\mathrm{MO}_{4}\right)_{\infty}$-tetrahedral chains in brownmillerite-type frameworks. Full ordering is achieved for a description in $12 \mathrm{mb}$ and Pnma, showing different relative but ordered chain arrangements for different layers, while the superposition of both arrangements results, on an average scale, in split positions for the in-plane oxygen and M-atoms, which can be described in the Imma space group symmetry.

Some oxides with brownmillerite type structure- such as $\mathrm{SrFeO}_{3-x}$ or $\mathrm{SrCoO}_{3-x}$-have been shown to exhibit oxygen mobility down to room temperature [13-15]. This makes brownmillerite-type oxides an attractive class of compounds for many technologically important applications in the field of solid state electrolytes, and more specifically for membranes or pure electrolytes in solid oxide fuel cells (SOFC) or for air separation, but equally important as sensor and electro catalysts.

When high oxygen mobility in brownmillerite type oxides merges with oxygen non-stoichiometry, this not only gives rise to complex oxygen defect structures at room temperature, but also induces phase transitions at high temperatures, which have a direct influence on the microstructure; i.e., on the twin domain structure of as-grown single crystals. Phases like $\mathrm{SrFeO}_{3-x}$ or $\mathrm{SrCoO}_{3-x}$ show a high temperature parent perovskite phase with cubic symmetry, which in addition is non-stoichiometric. Adjusting the appropriate oxygen stoichiometry corresponding to the ideal $\mathrm{A}_{2} \mathrm{~B}_{2} \mathrm{O}_{5}$ composition requires a perfect knowledge of the phase diagram; i.e., the oxygen stoichiometry at high temperatures as a function of the applied $\mathrm{p}\left(\mathrm{O}_{2}\right)$. However, while $\mathrm{SrFeO}_{2.5}$ can then be obtained by furnace cooling under controlled $\mathrm{p}\left(\mathrm{O}_{2}\right)$, this is no longer true for $\mathrm{SrCoO}_{2.5}$ under similar reaction conditions, as slow cooling results in a phase segregation and the formation of a Co-deficient modulated hexagonal modification $\mathrm{Sr}_{x} \mathrm{CoO}_{3}(x=14 / 11)$ [7]. Stoichiometric $\mathrm{SrCoO}_{2.5}$ can only be obtained by quenching from high temperatures, and is consequently a metastable phase at room temperature. Thereby, cooling from a cubic perovskite phase at high temperatures to a brownmillerite phase with orthorhombic symmetry at room temperature may generally go along with the formation of twin domains, which in this specific case can reach up to twelve different domains [16].

Other brownmillerite phases exist which are stoichiometric under normal reaction conditions but show different high temperature phase transitions. This is the case comparing $\mathrm{Ca}_{2} \mathrm{Fe}_{2} \mathrm{O}_{5}$ with $\mathrm{Sr}_{2} \mathrm{ScGaO}_{5}$. While $\mathrm{Sr}_{2} \mathrm{ScGaO}_{5}$ shows a phase transition towards the cubic perovskite phase above $1400{ }^{\circ} \mathrm{C}[17,18], \mathrm{Ca}_{2} \mathrm{Fe}_{2} \mathrm{O}_{5}$ does not. The case of $\mathrm{Sr}_{2} \mathrm{ScGaO}_{5}$ is peculiar, as the high temperature perovskite phase, once obtained, is kinetically stable - even during furnace cooling down to room temperature. On the other hand, $\mathrm{Ca}_{2} \mathrm{Fe}_{2} \mathrm{O}_{5}$ has no perovskite structure counterpart, and crystal growth leads directly from the melt to the brownmillerite framework. Such a situation is therefore completely different in terms of domain structure compared to $\mathrm{Sr}_{2}(\mathrm{Fe} / \mathrm{Co})_{2} \mathrm{O}_{5}$, as outlined above. It is thus evident that thermodynamic and kinetic stabilities play a crucial role during the formation 
of brownmillerite-type oxides, and especially during crystal growth. Additional complexity arises for non-stoichiometric $\mathrm{A}_{2} \mathrm{~B}_{2} \mathrm{O}_{5+\delta}$ phases, which can already undergo reversible oxygen intercalation reactions at room temperature, and the formation of complex twin structures have been reported for $\mathrm{SrFeO}_{3-\mathrm{x}}$ line phases with $x=0.5,0.25$, and 0.125 during the electrochemical oxidation reaction [16].

The aim of this article is to show how crystal growth might be influenced by the existence or not of high temperature phase transitions, and their respective impact on phase formation and structural stability. We focus here in particular on $\mathrm{Ca}_{2} \mathrm{Fe}_{2} \mathrm{O}_{5}$ (henceforth, $\mathrm{CFO}$ ) and $\mathrm{Sr}_{2} \mathrm{ScGaO}_{5}$ (in the following SSGO) single-crystal growth by the floating zone method, and their structural characterization by neutron and X-ray diffraction, as well as by SEM. Since both title compounds are line phases even up to high temperatures, oxygen fugacity is not a major issue perturbing crystal growth conditions in this respect.

\section{Results and Discussion}

\section{1. $\mathrm{Sr}_{2} \mathrm{ScGaO}_{5}$}

When synthesizing $\mathrm{Sr}_{2} \mathrm{ScGaO}_{5}$ by classical solid state reaction at $1200{ }^{\circ} \mathrm{C}$, the thermodynamically stable phase obtained shows a brownmillerite framework with $I 2 \mathrm{mb}$ space group at room temperature and unit cell parameters $a=5.91048(5) \AA, b=15.1594(1) \AA$, and $c=5.70926(4) \AA$ [18]. This structure is characterized by two important details: (i) the B-cation shows a specific order with Sc selectively on octahedral and $\mathrm{Ga}$ on tetrahedral sites; and (ii) the $(\mathrm{GaO} 4)_{\infty}$-tetrahedral chains show long range order for the zigzag arrangement, as shown in Figure 1. Upon heating, the symmetry changes around $300{ }^{\circ} \mathrm{C}$ towards Imma, indicating a statistical disorder of the $\mathrm{GaO}_{4}$-tetrahedra with the in-plane oxygen and Ga atoms on a split position. The ordered Sc/Ga-distribution underlines a particular stability for this configuration, even up to high temperatures, while the transition towards the average oxygen-deficient perovskite framework with cubic symmetry occurs only above $1300^{\circ} \mathrm{C}$ (as indicated in Figure 2). While covering even more than $150^{\circ} \mathrm{C}$, it is still not clear whether the orthorhombic/cubic phase transition is of first or second order. This becomes evident in Figure $2 \mathrm{~b}$ for the heating cycle with a rate of $2{ }^{\circ} \mathrm{C} / \mathrm{min}$. The reverse transition from cubic to orthorhombic is even more hindered, as the cubic phase remains stable even during slow furnace cooling at $2{ }^{\circ} \mathrm{C} / \mathrm{min}$. Since there is evidence that the cubic phase still contains predominantly $\mathrm{ScO}_{6}$ octahedra and $\mathrm{GaO}_{4}$ tetrahedra, the slow transformation kinetics is supposed to rely on the specific microstructure which consists in a simple picture of microdomains of the brownmillerite network, averaged by the coherence length of the diffraction method. In this way, the cubic-to-orthorhombic transition might be regarded as a reconstructive phase transition.

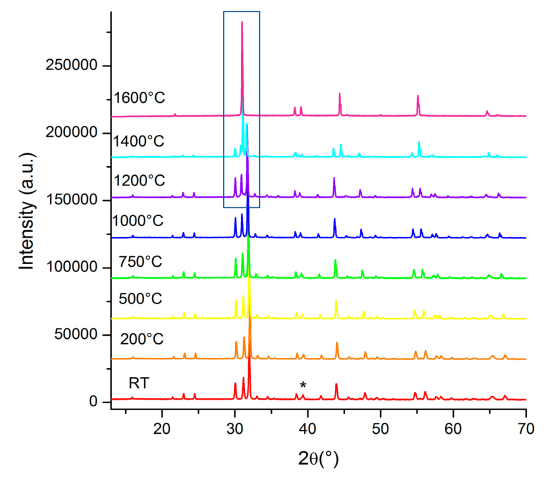

(a)

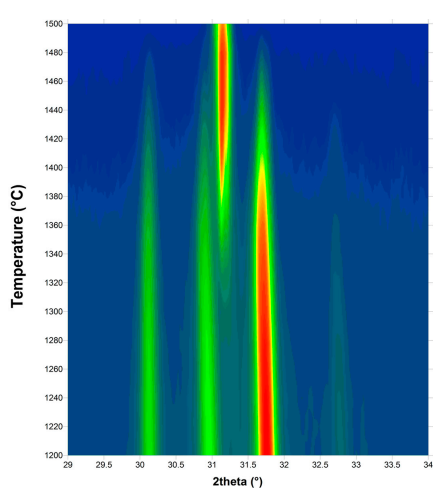

(b)

Figure 2. Phase transition from orthorhombic $\mathrm{Sr}_{2} \mathrm{ScGaO}_{5}$ (SSGO) with brownmillerite structure towards the cubic oxygen-deficient perovskite obtained by temperature-dependent $\mathrm{X}$-ray powder diffraction using a heating rate of $2{ }^{\circ} \mathrm{C} / \mathrm{min}$ (the diffraction peak at $39^{\circ}$ is from $\mathrm{Pt}$ sample holder) (RT: room temperature) (a); The outlined part is shown as a 2D-intensity plot (b), indicating that the transformation spans a range of more than $150^{\circ} \mathrm{C}$. 
A cubic $\mathrm{Sr}_{2} \mathrm{ScGaO}_{5}$ (c-SSGO) single crystal, grown by the Floating Zone method, is shown in Figure 3. The grown crystal had a diameter of $4 \mathrm{~mm}$ and $40-50 \mathrm{~mm}$ length. While polycrystalline feed and seed rods were white, the grown crystal was of transparent light-yellow colour in the first growth-start position, becoming brown beyond the first $10 \mathrm{~mm}$. The appearance of the colour is surprising, but the crystal becomes colourless after heating at $900{ }^{\circ} \mathrm{C}$ in vacuum.

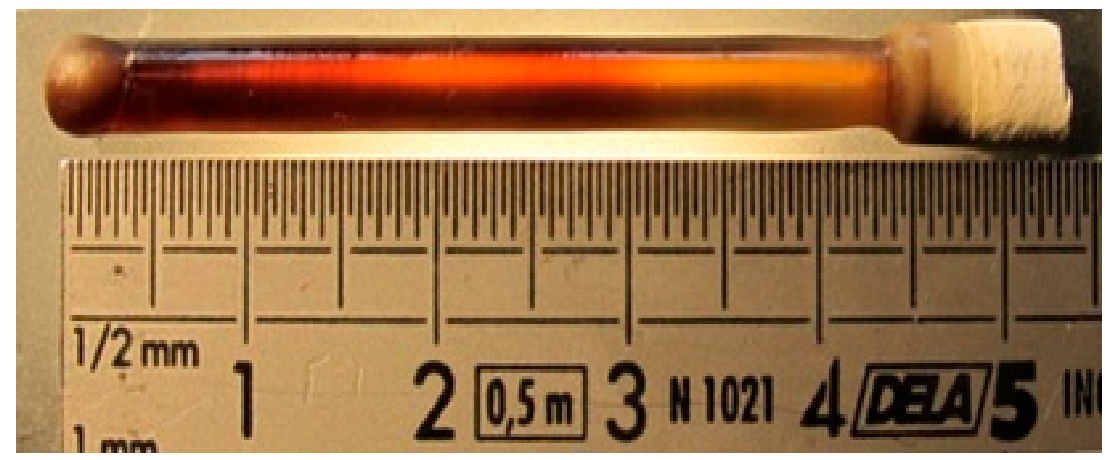

Figure 3. As-grown $\mathrm{Sr}_{2} \mathrm{ScGaO}_{5}$ single-crystal (cubic SSGO, c-SSGO).

Chemical composition and homogeneity of the crystals were checked by SEM coupled with EDX analysis. For this purpose, a slice of each crystal was taken perpendicular to the growth direction and polished mechanically. The crystals were found to be free of cracks or inclusions of secondary phases (Figure 4). EDX compositional analysis indicated a change in the stoichiometry in the first yellow part, for which the ratio Sc:Ga is not 1:1 (Table 1), as expected from the initial $\mathrm{Sr}_{2} \mathrm{ScGaO}_{5}$ chemical composition. The deposition of a fine white powder on the mirror furnace quartz tube indicated a mass loss due to evaporation from the molten during the growth process, and we analysed the evaporated compounds to be $\mathrm{SrO}$ and $\mathrm{Ga}_{2} \mathrm{O}_{3}$ (Table 1). For the brownish crystal, different points throughout the cross-section of the crystal were analysed to verify the chemical composition as well as its homogeneity. It was found that the atomic percentage of scandium, gallium, and strontium remains constant over the whole cross section, while the $\mathrm{Ga} / \mathrm{Sc}$ ratio was found to be 1 throughout the whole cross-section (see Table 1 and Figure 4), in agreement with the chemical formula of $\mathrm{Sr}_{2} \mathrm{ScGaO}_{5}$.
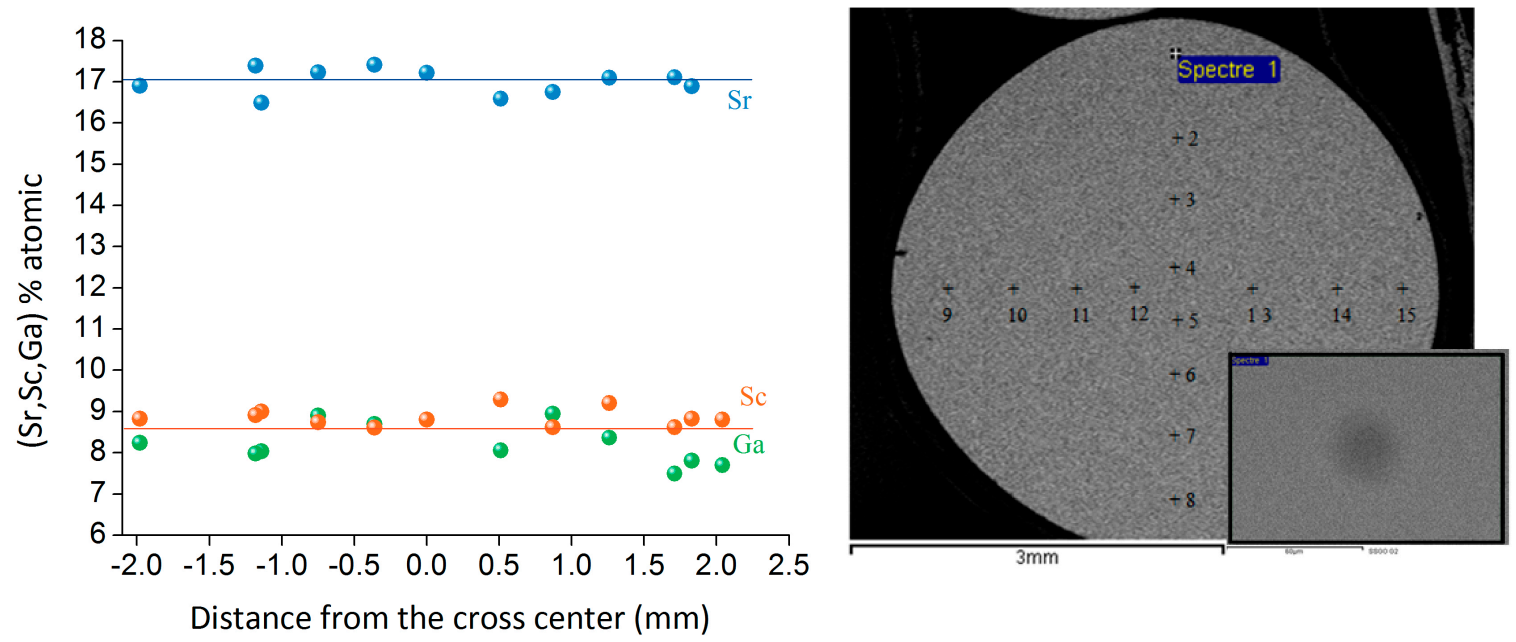

Figure 4. Chemical composition along the cross section of the as as-grown c-SSGO single crystal (left). (right) SEM cross section and analysed points. 
Table 1. Averaged elemental composition of the first yellow part and of the brownish as-grown single crystal, as well as the deposited powder on the quartz tube during crystal growth, checked by EDX.

\begin{tabular}{cccc}
\hline \multirow{2}{*}{ Element } & Yellow Part & Brown Part & Deposited Powder \\
\cline { 2 - 4 } & At $\%$ & At $\%$ & At $\%$ \\
\hline O & $58.01 \pm 6$ & $65.2 \pm 7$ & $75 \pm 8$ \\
Sc & $12.71 \pm 1$ & $8.6 \pm 1$ & - \\
Ga & $9.10 \pm 1$ & $8.9 \pm 1$ & $13.3 \pm 1$ \\
Sr & $20.9 \pm 2$ & $17.2 \pm 2$ & $11.7 \pm 1$ \\
\hline
\end{tabular}

A single-phase cubic structure was identified from X-ray powder diffraction, obtained from a crushed as-grown crystal. Structural refinement carried out using the Fullprof software [19] and a vacancy disordered $P m \overline{3} m$ model shows a monophasic compound with lattice parameters $a=3.9932(1) \AA$ And a unit cell volume equal to 63.6736(9) $\AA^{3}$.

The brownmillerite-to-cubic perovskite transition at high temperature is a classical order/disorder phase transition, as already reported for similar brownmillerite phases at high temperature $[17,20,21]$. The ordered brownmillerite is thermodynamically stable below $1300{ }^{\circ} \mathrm{C}$, while the average cubic phase forms above this temperature. The cubic modification can nevertheless be obtained metastable at room temperature, even in the form of a single crystal, allowing for the first time a $\mathrm{Sr}_{2} \mathrm{ScGaO}_{5}$ single crystal to be obtained in an oxygen-deficient perovskite structure. It is interesting to note that attempts to transform the c-SSGO single crystal towards the orthorhombic brownmillerite modification failed, even after annealing at $1450^{\circ} \mathrm{C}$ for more than one week.

The bulk crystalline quality of the as-grown crystal has been investigated on a centimeter-sized sample by neutron diffraction on the 4-circle neutron diffractometer 5C2 at the Laboratoire Léon Brillouin (LLB) [22]. Rocking curves measured in transversal $\omega$-scan mode for several Bragg peaks are given in Figure 5. The values of the full width half maximum (FWHM) for reflections with different orientation of the scattering vector are close to the instrumental resolution, thus confirming an excellent mosaicity of the crystal. Results of the structure refinement from single crystal neutron diffraction up to $0.89 \AA^{-1}$ in $\sin \Theta / \lambda$ (see Table 2) are reported in Table 2 using SHELXL (version 2014/2) [23]. For all refinements, the Sr occupancy has been fixed to unity, while oxygen site occupancies were refined. The B-cation site occupancy was constrained to be unity, inversely correlating Ga and Sc contributions. It becomes evident that the deviation from an equal Sc/Ga occupation on the B-cation site was found to be less than $2 \%$; the same error bar holds for the oxygen occupancies, which are statistically vacant by $1 / 6$. Strongly anisotropic oxygen displacement factors become evident, giving rise to a disc-shaped distribution of all oxygen atoms, as shown in Figure 6.
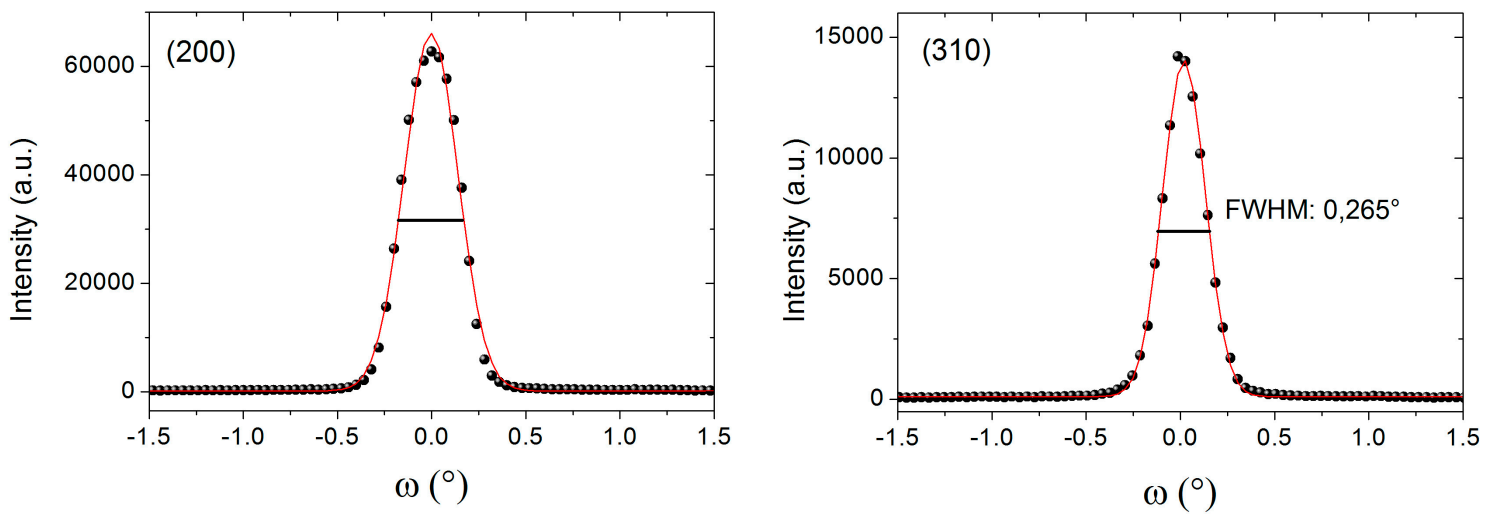

Figure 5. Rocking curves of the (200) and the (310) reflections for c-SSGO, crystal giving evidence of the excellent quality and good mosaicity of the grown single-crystal. FWHM: full width half maximum. 
Table 2. c-SSGO structure data obtained from single crystal neutron diffraction data, collected on diffractometer 5C2@LLB with $\lambda=0.83 \AA$, installed at the hot source of the ORPHEE reactor. Refinements were carried out in space group Pm-3m with unit cell parameter $a=3.9932 \AA$ (determined from $X$-ray powder diffraction (XRPD), $\mathrm{CuK}_{\alpha 1}$ ). One hundred and fifty two measured reflections $\left(\sin \theta / \lambda=0.72 \AA^{-1}\right),\left(49\right.$ unique) $R_{\text {int }}(\mathrm{hkl})=3.1 \%, R \mathrm{w}=10 \%, \mathrm{GooF}=1.23$.

\begin{tabular}{cccccc}
\hline Atom & $x$ & $y$ & $z$ & Occupancy & $U\left(\AA^{2}\right)$ \\
\hline Sr & 0 & 0 & 0 & 1.00 & $U_{\text {iso }}=0.0310(17)$ \\
Sc & $\frac{1}{2}$ & $\frac{1}{2}$ & $\frac{1}{2}$ & $0.521(41)$ & $U_{\text {iso }}=0.0312(13)$ \\
Ga & $\frac{1}{2}$ & $\frac{1}{2}$ & $\frac{1}{2}$ & $0.479(41)$ & $U_{\text {iso }}=0.0312(13)$ \\
$\mathrm{O}$ & 0 & $\frac{1}{2}$ & $\frac{1}{2}$ & $2.462(42)$ & $U_{11}=0.0390(32) U_{22}=U_{33}=0.0901(48)$ \\
\hline
\end{tabular}

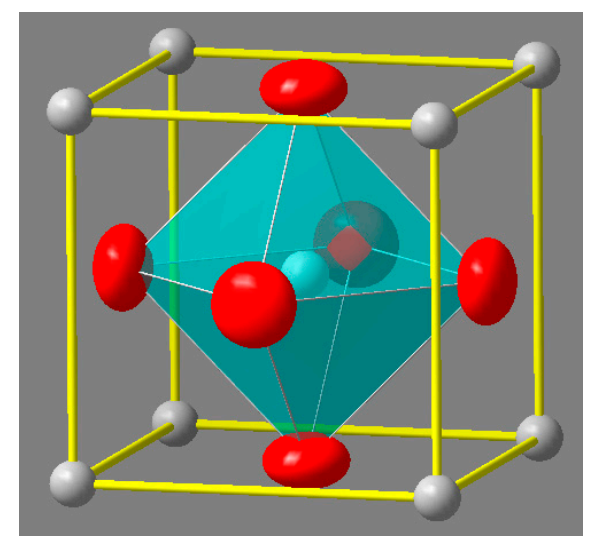

Figure 6. Oxygen-deficient cubic perovskite $\mathrm{Sr}_{2} \mathrm{ScGaO}_{5}$ structure obtained at room temperature from neutron single crystal diffraction on 5C2 at the Laboratoire Léon Brillouin (LLB; Orphée reactor, France). While reasonable isotropic displacements are observed for $\mathrm{Sr}$ and $(\mathrm{Sc} / \mathrm{Ga})$, oxygen atoms show strong anisotropic displacement factors. Outlined are ellipsoids with $50 \%$ probability for all atoms.

\section{2. $\mathrm{Ca}_{2} \mathrm{Fe}_{2} \mathrm{O}_{5}$}

As stated above, $\mathrm{Ca}_{2} \mathrm{Fe}_{2} \mathrm{O}_{5}$ is known as a stoichiometric line phase without significant variation of the oxygen stoichiometry, up to at least $120{ }^{\circ} \mathrm{C}$. It crystallises in the brownmillerite framework with Pnma symmetry (i.e., ordered $\left(\mathrm{FeO}_{4}\right)_{\infty}$-tetrahedral chains), but with a different stacking arrangement compared to the room temperature modification of $\mathrm{Sr}_{2} \mathrm{ScGaO}_{5}$ with $I 2 \mathrm{mb}$ space group (see Figure 1). While no cubic perovskite phase has been reported so far for $\mathrm{Ca}_{2} \mathrm{Fe}_{2} \mathrm{O}_{5}$, Krüger et al. [24,25] described an incommensurate modulated structure with superspace group Imma(00 $\gamma) s 00$ and $\gamma=0.5588$ at $T=830{ }^{\circ} \mathrm{C}$, involving complex ordering of the $\left(\mathrm{FeO}_{4}\right)_{\infty}$ chains within, and also along the stacking of the tetrahedral layers along the $b$ axis [24]. The phase transition from the incommensurate to commensurate phase also induces the formation of extended defects, such as anti-phase boundaries, which have been interpreted to originate from a phase shift of the tilting sequence of the $\left(\mathrm{FeO}_{4}\right)_{\infty}$ zigzag chains [25]. On top of the structural complexity, these lattice defects have been reported to have a direct influence on the oxygen mobility [26]. $\mathrm{Ca}_{2} \mathrm{Fe}_{2} \mathrm{O}_{5}$ is congruently melting [27,28], which significantly helps for the single crystal growth. The applied growth conditions reported in [28] yielded a $\mathrm{Ca}_{2} \mathrm{Fe}_{2} \mathrm{O}_{5}$ single-crystal (CFO) of $6 \mathrm{~mm}$ in diameter and $120 \mathrm{~mm}$ in length, showing a shiny silver-black surface with metallic lustre, as shown in Figure 7. Powder diffraction carried out on crushed parts of the as-grown single crystals yielded lattice parameters of $a=5.4272(4) \AA, b=14.7640(1) \AA$, and $c=5.59724(4) \AA$, in very good agreement with previous reports $[12,28,29]$. The corresponding XRD pattern is shown in Figure 8a. Pattern profile refinement carried out in the profile matching mode through the Fullprof software [19] and Pnma space group shows a monophasic compound. We underline a strong orthorhombicity for $\mathrm{Ca}_{2} \mathrm{Fe}_{2} \mathrm{O}_{5}$, which will become important when discussing the formation of twin domains, since the probability of obtaining mono-domain single crystals increases directly with the orthorhombicity. 
Twinning in brownmillerite single crystals has been extensively discussed in [16]. The quality of the as-grown crystal was first investigated by $\mathrm{X}$-ray Laue back diffraction. Laue diffractograms were taken along the length of the crystal, and also in several positions along the cross-section. All the Laue patterns are consistent, and showed that the crystal growth direction is only few degrees away from [101], as shown in Figure 8b.

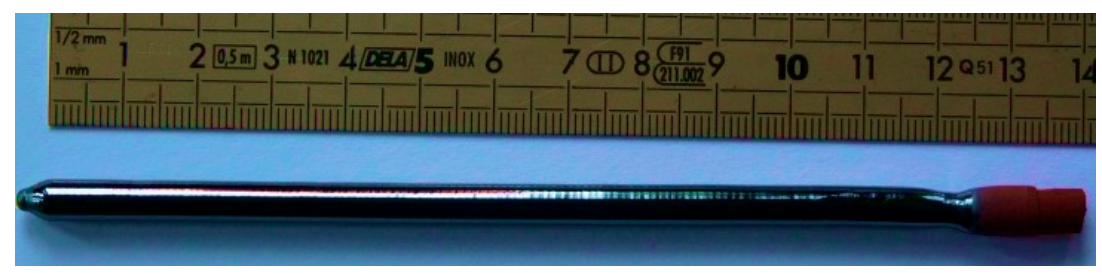

Figure 7. As-grown $\mathrm{Ca}_{2} \mathrm{Fe}_{2} \mathrm{O}_{5}$ single crystal obtained by the floating zone method.
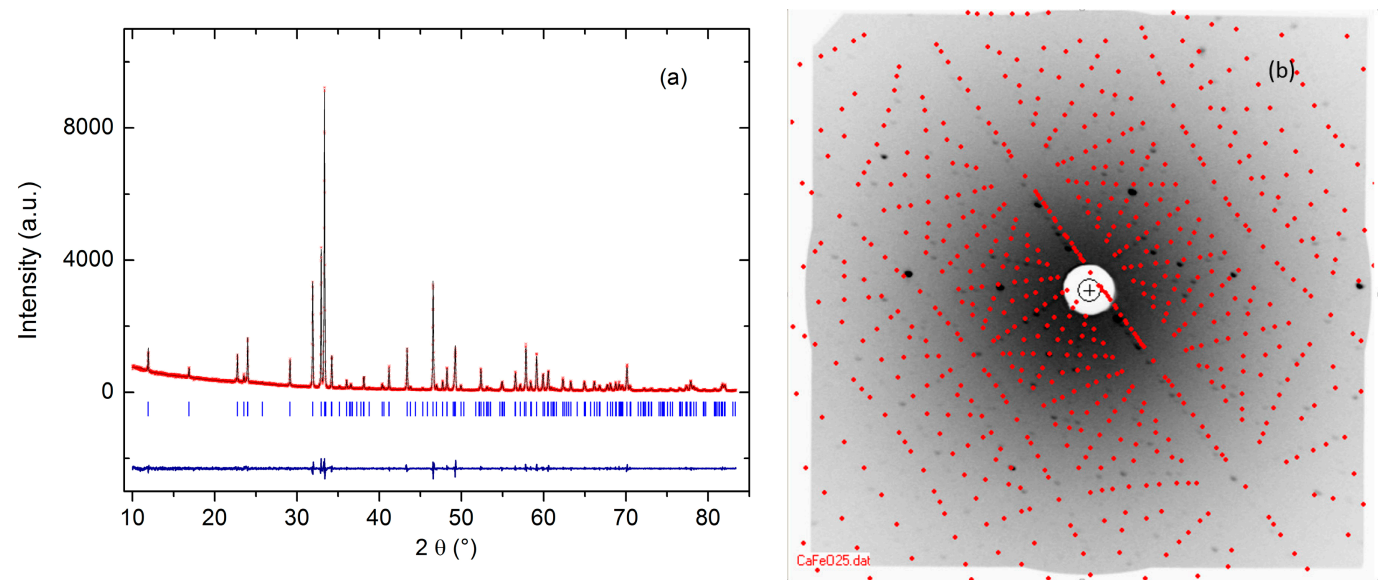

Figure 8. (a) Observed, calculated, and difference plots of XRD (Bruker D8 Advance, $\mathrm{Cu} \mathrm{K}_{\alpha 1}$ ) patterns of the as-grown single $\mathrm{Ca}_{2} \mathrm{Fe}_{2} \mathrm{O}_{5}$ crystal in the Pnma space group, obtained in profile matching mode. Vertical bars are related to the calculated Bragg reflection positions; (b) X-ray Laue back diffraction pattern taken on the middle of the cross-section of the crystal, showing the [101] growth direction (as obtained by OrientExpress).

The bulk crystalline quality of the as-grown crystal—eventually including possible twinning —has been checked on centimetre-sized samples by single crystal neutron diffraction on the four-circle diffractometer $5 \mathrm{C} 2$, installed at the hot source of the LLB. To this end, the crystals were aligned with the $b$-axis perpendicular to the diffraction plane of the diffractometer; pure transversal scans ( $\omega$ scans) were carried out for characteristic reflections such as $(h 00),(h h 0)$, and $(00 \ell)$, in order to determine peak width and eventually twinning.

As seen from Figure 9, the FWHM for all reflections (measured in transversal mode) is within or close to the instrumental resolution [22]. The rocking curve of, for example, the (400) reflection indicates a FWHM of the as-grown CFO crystals to be on the order of $0.2^{\circ}$. The $\omega$-scans for the $(h h 0)$ reflections (i.e., the $(-2-20)$ and the equivalent $(-220)$ reflections) show unique reflections, confirming that no twinning as discussed in [30] occurred during crystal growth. The absence of twinning in nearly all batches we carried out can also be interpreted as evidence of the absence of a cubic perovskite modification, at least up to the melting temperature of $\mathrm{Ca}_{2} \mathrm{Fe}_{2} \mathrm{O}_{5}$, which is around $1350{ }^{\circ} \mathrm{C}$. In the case of the presence of a cubic parent phase, one would expect the formation of twin domains, as is the case for $\mathrm{Sr}_{2} \mathrm{Fe}_{2} \mathrm{O}_{5}$ [16]; instead, the as-grown crystals do not show any observable macroscopic twin domains, but uniformly-shaped crystal ingot. 

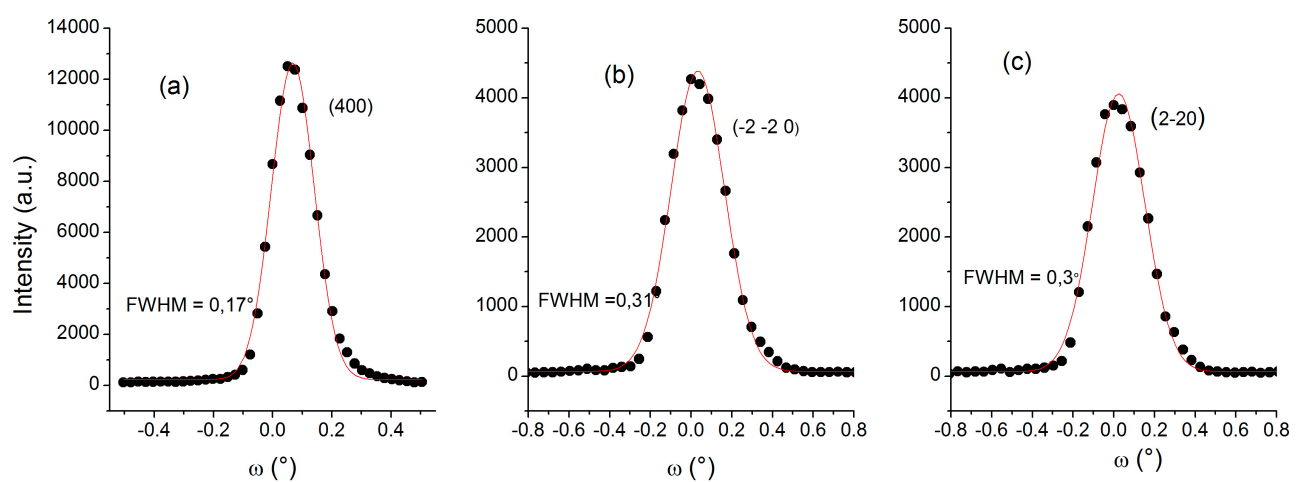

Figure 9. Neutron rocking curve of the $\mathrm{Ca}_{2} \mathrm{Fe}_{2} \mathrm{O}_{5}$ (CFO) single crystal (400) (a)- and (220) (b and c)-type Bragg reflections, obtained by single crystal neutron diffraction on 5C2@LLB in Saclay $(\lambda=0.83 \AA$ ).

\subsection{Oxygen Mobility and General Scientific Interest of Cubic $\mathrm{Sr}_{2} \mathrm{ScGaO}_{5}$ and $\mathrm{Ca}_{2} \mathrm{Fe}_{2} \mathrm{O}_{5}$}

Both title compounds show oxygen deficiency, and are thus interesting as oxygen ion conductors, with applications as membranes or electrolytes. The temperature for oxygen mobility to set in can be easily determined by ${ }^{18} \mathrm{O} /{ }^{16} \mathrm{O}$ isotope exchange behaviour and analysing related mass loss by thermogravimetric analysis. Both compounds show only very low electronic conductivity, but their oxygen mobility sets in at around $450{ }^{\circ} \mathrm{C}$ and $500{ }^{\circ} \mathrm{C}$ for $\mathrm{Ca}_{2} \mathrm{Fe}_{2} \mathrm{O}_{5}$ and $\mathrm{Sr}_{2} \mathrm{ScGaO}_{5}$, respectively. These temperatures are interestingly low for stoichiometric ion transport to take place, as necessary for oxygen separation membranes. Isotope exchange experiments are illustrated for both compounds in Figure 10. While the exchange temperatures for both systems are similar, the exchange kinetics are not. Using a heating rate of $5{ }^{\circ} \mathrm{C} / \mathrm{min}$ in both cases, the exchange for $\mathrm{CFO}$ is completed at $600{ }^{\circ} \mathrm{C}$, while for c-SSGO, exchange is still not finished upon reaching $900^{\circ} \mathrm{C}$. The temperature was then held $3 \mathrm{~h}$ at $900{ }^{\circ} \mathrm{C}$ to complete the reaction. Simultaneous to the change of the mass loss, the ${ }^{18} \mathrm{O} /{ }^{16} \mathrm{O}$ exchange was monitored by mass spectroscopy. The more rapid isotope exchange for $\mathrm{Ca}_{2} \mathrm{Fe}_{2} \mathrm{O}_{5}$ is probably related to the higher catalytic surface activity in the case of $\mathrm{Fe}^{3+}$ compared to the $d^{0} / d^{10}$ configuration of $\mathrm{Sc} / \mathrm{Ga}$, but also to the fact that $\mathrm{FeO}_{\mathrm{x}}$ polyhedra are more flexible [16], and not as rigid as reported for $\mathrm{ScO}_{6}$ octahedra or $\mathrm{GaO}_{4}$ tetrahedra $[12,18]$ —even in an average cubic symmetry. A similar tendency was already observed comparing $\mathrm{Ca}_{2} \mathrm{Fe}_{2} \mathrm{O}_{5}$ and $\mathrm{Ca}_{2} \mathrm{FeAlO}_{5}$ [3], where the pure $\mathrm{CFO}$ showed a much higher conductivity.
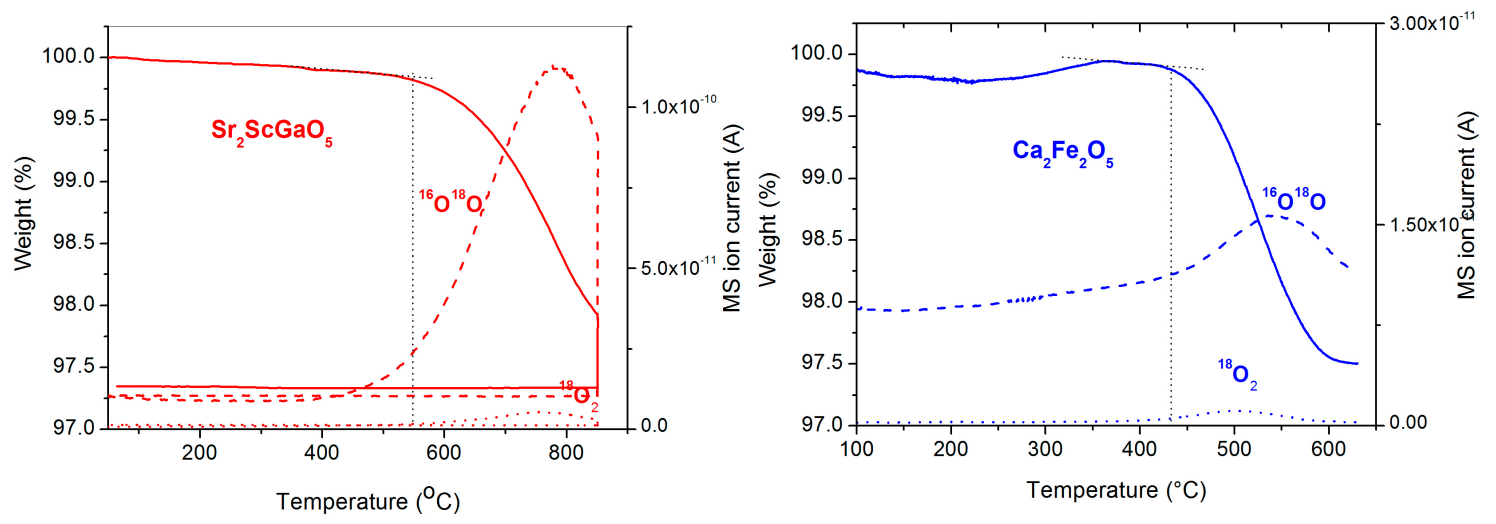

Figure 10. Oxygen isotope exchange behaviour of cubic $\mathrm{Sr}_{2} \mathrm{ScGa}^{18} \mathrm{O}_{5}$ (left) and $\mathrm{Ca}_{2} \mathrm{Fe}_{2}{ }^{18} \mathrm{O}_{5}$ (right) followed by TG with a heating rate of $5{ }^{\circ} \mathrm{C} / \mathrm{min}$. The mass loss is related to the exchange of ${ }^{18} \mathrm{O}$ to ${ }^{16} \mathrm{O}$, indicating that oxygen exchange is taking place as a solid/gas exchange reaction. For a $100 \%$ enrichment, the theoretical mass loss is $2.65 \%$ and $3.67 \%$ for c-SSGO and CFO, respectively. The ${ }^{18} \mathrm{O} /{ }^{16} \mathrm{O}$ exchange is indicated by simultaneously-measured mass signals corresponding to ${ }^{18} \mathrm{O}-{ }^{16} \mathrm{O}$ and ${ }^{18} \mathrm{O}-{ }^{18} \mathrm{O}$. 


\section{Materials and Methods}

Single crystals of $\mathrm{Ca}_{2} \mathrm{Fe}_{2} \mathrm{O}_{5}$ and $\mathrm{Sr}_{2} \mathrm{ScGaO}_{5}$ were grown using an optical mirror furnace (NEC SC2, Tokyo, Japan) equipped with two $500 \mathrm{~W}$ halogen lamps as heat source and two ellipsoidal mirrors. Both crystal growths were performed in air atmosphere with a typical traveling rate of $1-2 \mathrm{~mm} / \mathrm{h}$, while the upper and lower shafts were rotated in opposite directions at $25 \mathrm{rpm}$.

The starting polycrystalline compounds of were prepared using standard solid-state chemistry methods. High purity $\mathrm{SrCO}_{3}\left(99.995 \%\right.$, ALDRICH), $\mathrm{Ga}_{2} \mathrm{O}_{3}$ (99.99\%, ALDRICH), and $\mathrm{Sc}_{2} \mathrm{O}_{3}$ (REacton 99.99\% REO, ALFA AESAR) were thoroughly mixed and heated in air at $1200{ }^{\circ} \mathrm{C}$ for $48 \mathrm{~h}$ with intermediate re-grinding, to obtain pure $\mathrm{Sr}_{2} \mathrm{ScGaO}_{5} . \mathrm{Ca}_{2} \mathrm{Fe}_{2} \mathrm{O}_{5}$ was obtained by mixing $\mathrm{CaCO}_{3}$ (99.95\%) and $\mathrm{Fe}_{2} \mathrm{O}_{3}(99.99 \%)$ and then heating in air at $1000{ }^{\circ} \mathrm{C}$ for $48 \mathrm{~h}$. Calcination was repeated twice with intermediate grinding. Finally, the sample was annealed $1200{ }^{\circ} \mathrm{C}$ for $24 \mathrm{~h}$. Seed and feed rods for crystal growth were obtained by hydrostatic pressing of the obtained powders at 10 bars in a cylindrical latex tube of 6-8 $\mathrm{mm}$ in diameter and $100 \mathrm{~mm}$ in length. The rods were then sintered in air at $1200{ }^{\circ} \mathrm{C}$ for $24 \mathrm{~h}$ to obtain dense polycrystalline rods.

Laboratory X-ray powder patterns up to $1600{ }^{\circ} \mathrm{C}$ were collected on a Panalytical Empyrean diffractometer $\left(\mathrm{Cu} \mathrm{K} \mathrm{K}_{\alpha 1,2}\right)$, equipped with the HTK $16 \mathrm{~N}$ Anton Parr high temperature chamber.

The crystal quality and elemental composition were checked by Scanning Electron Microscopy (SEM) analysis using a JEOL JSM 6400 (JEOL USA Inc, Tokyo, Japan) microscope equipped with an OXFORD INCA EDS (Oxford Instruments, Oxford, UK) instrument for atomic recognition via X-ray fluorescence spectroscopy. SEM/EDS analyses were performed on a cross section (6-7 mm in diameter) of all grown crystals, after an accurate surface polishing and cleaning. Samples were also characterized by isotopic exchange ${ }^{18} \mathrm{O} /{ }^{16} \mathrm{O}$ and thermogravimetric analysis (TGA) coupled with mass spectrometry (MS). Thermogravimetric measurements were carried out on a NETSCH thermobalance Jupiter STA 449C (NETZSCH-Gerätebau GmbH, Selb, Germany) equipped with a PFEIFFER VACUUM Thermo Star mass spectrometer (Pfeiffer Vacuum GmbH, Asslar City, Germany).

Neutron diffraction was performed on the $5 \mathrm{C} 2$ single crystal diffractometer installed at the LLB (ORPHEE reactor in Saclay, France) with $\lambda=0.83 \AA$.

Laue diffraction was obtained using a tungsten anode $(50 \mathrm{kV})$ on a Seifert generator in backscattering mode, equipped with an image plate detector. Data were analysed using the Orient Express V3.3 software.

\section{Conclusions}

Crystal growth of brownmillerite type oxides is discussed, depending on the high temperature parent phase symmetry and related kinetics of the phase transformations, which may lead to different defect structures and associated twin domains. Compared to $\mathrm{SrFeO}_{3-x}$ and $\mathrm{SrCoO}_{3-x}$, the kinetics of the high temperature cubic to low temperature orthorhombic phase transition of $\mathrm{Sr}_{2} \mathrm{ScGaO}_{5}$ is very slow, allowing the cubic symmetry to be preserved, even down to room temperature. This allowed an oxygen deficient perovskite oxide to be obtained for $\mathrm{Sr}_{2} \mathrm{ScGaO}_{5}$ in the form of a single crystal. The fact that $\mathrm{Ca}_{2} \mathrm{Fe}_{2} \mathrm{O}_{5}$ single crystals are obtained for almost all batches untwinned implies that no cubic perovskite high temperature parent phase exists, and that crystallization of the orthorhombic brownmillerite phase occurs directly from the melt. The strong orthorhombicity thereby favors the formation of non-twinned crystals. It is also evident that due to the different volatility of the components, the growth conditions generally need to be optimized in a rigorous and reproducible way, in order to draw conclusions on possible differences in the structural and physical properties. This is not only a mandatory issue for non-stoichiometric oxides, but also in the case of solid solutions (e.g., for variable B-site cation stoichiometry, as is the case for $\mathrm{Sr}_{2} \mathrm{ScGaO}_{5}$ ). The composition of the seed rod and the melt thus play a crucial role for the final crystal stoichiometry. Keeping all these parameters in consideration, we succeeded in the growth of high quality and centimeter-sized brownmillerite-type $\mathrm{CaFeO}_{2.5}$, and perovskite-type $\mathrm{Sr}_{2} \mathrm{ScGaO}_{5}$ single crystals by floating zone method. The availability of large crystals enabled single crystal neutron diffraction-complementary to laboratory X-ray Laue 
diffraction-to evaluate their bulk crystal quality. We also want to underline the importance of accessing neutron structure factors up to high momentum transfer for a precise structure analysis, in order to allow high quality structure determination with meaningful displacement factors, even for disordered and/or non-stoichiometric compounds.

Acknowledgments: We acknowledge Bernard Fraisse of the "Plateforme d'Analyse et de Caractérisation du Pôle Chimie Balard", Montpellier, for X-rays thermodiffraction measurements. We would like to thank the Laboratoire Léon Brillouin (LLB, Saclay, France) for the allocation of the neutron beam time. We also acknowledge Kazimierz Conder, PSI-Villigen, for TGA measurements. This work was financially supported through the French National Agency Research (ANR) project "Assisted Mechanisms for Oxygen Ionic conduction in non-Stoichiometric oxides" (AMOXIS, No. ANR-14-CE05-0016-02).

Author Contributions: Werner Paulus and Monica Ceretti conceived and designed the experiments; Monica Ceretti and Serena Corallini performed the experiments; Werner Paulus, Monica Ceretti and Serena Corallini analyzed the data; Monica Ceretti and Werner Paulus wrote the paper.

Conflicts of Interest: The authors declare no conflict of interest.

\section{References}

1. Abakumov, A.M.; Rozova, M.G.; Pavlyuk, B.P.; Lobanov, M.V.; Antipov, E.V.; Lebedev, O.I.; van Tendeloo, G.; Ignatchik, O.L.; Ovtchenkov, E.A.; Koksharov, Y.A.; et al. Synthesis, crystal structure, and magnetic properties of a novel layered manganese oxide $\mathrm{Sr}_{2} \mathrm{MnGaO}_{5+\delta}$. J. Solid State Chem. 2001, 160, 353-361. [CrossRef]

2. Abakumov, A.M.; Alekseeva, A.M.; Rozova, M.G.; Antipov, E.V.; Lebedev, O.I.; van Tendeloo, G. Ordering of tetrahedral chains in the $\mathrm{Sr}_{2} \mathrm{MnGaO}_{5+\delta}$ brownmillerite. J. Solid State Chem. 2003, 174, 319-328. [CrossRef]

3. Shaula, A.L.; Pivak, Y.V.; Waerenborgh, J.C.; Gaczynski, P.; Yaremchenko, A.A.; Kharton, V.V. Ionic conductivity of brownmillerite-type calcium ferrite under oxidizing conditions. Solid State Ion. 2006, 177, 2923-2930. [CrossRef]

4. Hadermann, J.; Abakumov, A.M.; D'Hondt, H.; Kalyuzhnaya, A.S.; Rozova, M.G.; Markina, M.M.; Mikheev, M.G.; Tristan, N.; Klingeler, R.; Buchner, B.; et al. Synthesis and crystal structure of the $\mathrm{Sr}_{2} \mathrm{Al}_{1.07} \mathrm{Mn}_{0.93} \mathrm{O}_{\mathrm{G}}$ brownmillerite. J. Mater. Chem. 2007, 17, 692-698. [CrossRef]

5. Yao, T.; Uchimoto, Y.; Kinuhata, M.; Inagaki, T.; Yoshida, H. Crystal structure of Ga-doped $\mathrm{Ba}_{2} \mathrm{In}_{2} \mathrm{O}_{5}$ and its oxide ion conductivity. Solid State Ion. 2000, 132, 189-198. [CrossRef]

6. Goodenough, J.B.; Ruiz-Diaz, J.E.; Zhen, Y.S. Oxide-ion conduction in $\mathrm{Ba}_{2} \mathrm{In}_{2} \mathrm{O}_{5}$ and $\mathrm{Ba}_{3} \mathrm{In}_{2} \mathrm{MO}_{8}(\mathrm{M}=\mathrm{Ce}, \mathrm{Hf}$, or Zr). Solid State Ion. 1990, 44, 21-31. [CrossRef]

7. Gourdon, O.; Petricek, V.; Dusek, M.; Bezdicka, P.; Durovic, S.; Gyepesova, D.; Evain, M. Determination of the modulated structure of $\mathrm{Sr}_{14 / 11} \mathrm{CoO}_{3}$ through a $(3+1)$-dimensional space description and using non-harmonic adps. Acta Crystallogr. B 1999, 55, 841-848. [CrossRef] [PubMed]

8. Alonso, J.A.; Martínez-Lope, M.J.; García-Muñoz, J.L.; Fernández-Díaz, M.T. A structural and magnetic study of the defect perovskite $\mathrm{LaNiO}_{2.5}$ from high-resolution neutron diffraction data. J. Phys. Condens. Matter 1997, 9, 6417. [CrossRef]

9. Vidyasagar, K.; Reller, A.; Gopalakrishnan, J.; Rao, C.N.R. Oxygen vacancy ordering in superlatives of the two novel oxides, $\mathrm{La}_{2} \mathrm{Ni}_{2} \mathrm{O}_{5}$ and $\mathrm{La}_{2} \mathrm{Co}_{2} \mathrm{O}_{5}$, prepared by low temperature reduction of the parent perovskites. J. Chem. Soc. Chem. Commun. 1985, 7-8. [CrossRef]

10. Reller, A.; Thomas, J.M.; Jefferson, D.A.; Uppal, M.K. Superstructures formed by the ordering of vacancies in a selective oxidation catalyst: Grossly defective $\mathrm{CaMnO}_{3}$. In Proceedings of the Royal Society of London. A. Mathematical and Physical Sciences; The Royal Society: London, UK, 1984; Volume 394, pp. 223-241.

11. Reller, A.; Jefferson, D.A.; Thomas, J.M.; Uppal, M.K. Oxygen vacancy ordering in a selective oxidation catalyst: Calcium manganese oxide $\left(\mathrm{CaMnO}_{2.8}\right)$. J. Phys. Chem. 1983, 87, 913-914. [CrossRef]

12. Paulus, W.; Schober, H.; Eibl, S.; Johnson, M.; Berthier, T.; Hernandez, O.; Ceretti, M.; Plazanet, M.; Conder, K.; Lamberti, C. Lattice dynamics to trigger low temperature oxygen mobility in solid oxide ion conductors. J. Am. Chem. Soc. 2008, 130, 16080-16085. [CrossRef] [PubMed]

13. Le Toquin, R.; Paulus, W.; Cousson, A.; Prestipino, C.; Lamberti, C. Time-resolved in situ studies of oxygen intercalation into $\mathrm{SrCoO}_{2.5}$, performed by neutron diffraction and X-ray absorption spectroscopy. J. Am. Chem. Soc. 2006, 128, 13161-13174. [CrossRef] [PubMed] 
14. Inoue, S.; Kawai, M.; Ichikawa, N.; Kageyama, H.; Paulus, W.; Shimakawa, Y. Anisotropic oxygen diffusion at low temperature in perovskite-structure iron oxides. Nat. Chem. 2010, 2, 213-217. [CrossRef] [PubMed]

15. Nemudry, A.; Weiss, P.; Gainutdinov, I.; Boldyrev, V.; Schollhorn, R. Room temperature electrochemical redox reactions of the defect perovskite $\mathrm{SrFeO}_{2.5+x}$. Chem. Mater. 1998, 10, 2403-2411. [CrossRef]

16. Maity, A.; Dutta, R.; Penkala, B.; Ceretti, M.; Letrouit-Lebranchu, A.; Chernyshov, D.; Perichon, A.; Piovano, A.; Bossak, A.; Meven, M.; et al. Solid-state reactivity explored in situ by synchrotron radiation on single crystals: From $\mathrm{SrFeO}_{2.5}$ to $\mathrm{SrFeO}_{3}$ via electrochemical oxygen intercalation. J. Phys. D Appl. Phys. 2015, 48, 504004. [CrossRef]

17. Chernov, S.V.; Dobrovolsky, Y.A.; Istomin, S.Y.; Antipov, E.V.; Grins, J.; Svensson, G.; Tarakina, N.V.; Abakumov, A.M.; Van Tendeloo, G.; Eriksson, S.G.; et al. $\mathrm{Sr}_{2} \mathrm{GaScO}_{5}, \mathrm{Sr}_{10} \mathrm{Ga}_{6} \mathrm{Sc}_{4} \mathrm{O}_{25}$, and $\mathrm{SrGa}_{0.75} \mathrm{Sc}_{0.25} \mathrm{O}_{2.5}$ : A play in the octahedra to tetrahedra ratio in oxygen-deficient perovskites. Inorg. Chem. 2012, 51, 1094-1103. [CrossRef] [PubMed]

18. Corallini, S.; Ceretti, M.; Silly, G.; Piovano, A.; Singh, S.; Stern, J.; Ritter, C.; Ren, J.; Eckert, H.; Conder, K.; et al. One-dimensional oxygen diffusion mechanism in $\mathrm{Sr}_{2} \mathrm{GaScO}_{5}$ electrolyte explored by neutron and synchrotron diffraction, 17o nmr, and density functional theory calculations. J. Phys. Chem. C 2015, 119, 11447-11458. [CrossRef]

19. Rodríguez-Carvajal, J. Recent developments of the program FULLPROF. Commission for powder diffraction. IUCr Newsl. 2001, 26, 12-19.

20. Goodenough, J.B.; Manthiram, A.; Kuo, J.F. Oxygen diffusion in perovskite-related oxides. Mater. Chem. Phys. 1993, 35, 221-224. [CrossRef]

21. Didier, C.; Claridge, J.; Rosseinsky, M. Crystal structure of brownmillerite $\mathrm{Ba}_{2} \mathrm{InGaO}_{5}$. J. Solid State Chem. 2014, 218, 38-43. [CrossRef]

22. 5C2: Hot Neutron Four-Circle Diffractometer at LLB. Available online: http://www-llb.cea.fr/en/fr-en/ spectro/5c2/5c2.html (accessed on 20 September 2016).

23. Sheldrick, G. A short history of shelx. Acta Crystallogr. A 2008, 64, 112-122. [CrossRef] [PubMed]

24. Krüger, H.; Kahlenberg, V. Incommensurately modulated ordering of tetrahedral chains in $\mathrm{Ca}_{2} \mathrm{Fe}_{2} \mathrm{O}_{5}$ at elevated temperatures. Acta Crystallogr. B Struct. Sci. 2005, 61, 656-662. [CrossRef] [PubMed]

25. Krüger, H.; Kahlenberg, V.; Petrícek, V.; Phillipp, F.; Wertl, W. High-temperature structural phase transition in $\mathrm{Ca}_{2} \mathrm{Fe}_{2} \mathrm{O}_{5}$ studied by in-situ $\mathrm{X}$-ray diffraction and transmission electron microscopy. J. Solid State Chem. 2009, 182, 1515-1523. [CrossRef]

26. Gupta, K.; Singh, S.; Ceretti, M.; Rao, M.S.R.; Paulus, W. Scaling of extended defects in nano-sized brownmillerite $\mathrm{CaFeO}_{2.5}$. Phys. Status Solidi A Appl. Mater. Sci. 2013, 210, 1771-1777. [CrossRef]

27. Maljuk, A.; Strempfer, J.; Lin, C.T. Floating zone growth and characterization of $\mathrm{Ca}_{2} \mathrm{Fe}_{2} \mathrm{O}_{5}$ single crystals. J. Cryst. Growth 2003, 258, 435-440. [CrossRef]

28. Ceretti, M.; Piovano, A.; Cousson, A.; Berthier, T.; Meven, M.; Agostini, G.; Schefer, J.; Hernandez, O.; Lamberti, C.; Paulus, W. Growth and characterization of large high quality brownmillerite $\mathrm{CaFeO}_{2.5}$ single crystals. CrystEngComm 2012, 14, 5771-5776. [CrossRef]

29. Berastegui, P.; Eriksson, S.G.; Hull, S. A neutron diffraction study of the temperature dependence of $\mathrm{Ca}_{2} \mathrm{Fe}_{2} \mathrm{O}_{5}$. Mater. Res. Bull. 1999, 34, 303-314. [CrossRef]

30. Paulus, W.; Cousson, A.; Dhalenne, G.; Berthon, J.; Revcolevschi, A.; Hosoya, S.; Treutmann, W.; Heger, G.; le Toquin, R. Neutron diffraction studies of stoichiometric and oxygen intercalated $\mathrm{La}_{2} \mathrm{NiO}_{4}$ single crystals. Solid State Sci. 2002, 4, 565-573. [CrossRef]

(C) 2016 by the authors; licensee MDPI, Basel, Switzerland. This article is an open access article distributed under the terms and conditions of the Creative Commons Attribution (CC-BY) license (http://creativecommons.org/licenses/by/4.0/). 